\title{
Correction to: Molecular phylogeny of the Nearctic and Mesoamerican freshwater mussel genus Megalonaias
}

\author{
John M. Pfeiffer • Ashley E. Sharpe • Nathan A. Johnson • Kitty F. Emery • \\ Lawrence M. Page
}

Published online: 18 December 2017

(C) The Author(s) 2017

\section{Correction to: Hydrobiologia \\ https://doi.org/10.1007/s10750-017-3441-7}

Due to an unfortunate mistake during the production process of the original publication, part of Table 1 was omitted. Hence, the original article has been corrected. The missing section (region 'Mobile') of Table 1 is also published on the following page. Springer Nature regrets the error and accepts sole responsibility.

The original article can be found online at https://doi.org/10.1007/s10750-017-3441-7.

J. M. Pfeiffer $(\bowtie) \cdot$ K. F. Emery · L. M. Page

Florida Museum of Natural History, University of Florida, Gainesville, FL, USA

e-mail: Jpfeiffer@ufl.edu
A. E. Sharpe
Center for Tropical Paleoecology and Archaeology,
Smithsonian Tropical Research Institute, Balboa-Ancón,
Panama
N. A. Johnson
US Geological Survey, Wetland and Aquatic Research
Center, Gainesville, FL, USA 
Table 1 Regional assignment of all Megalonaias specimens analyzed along with voucher numbers, collection localities, and GenBank accession numbers

\begin{tabular}{lllllll}
\hline Region & Tissue ID & Voucher & River & Locality & COI & ITS1 \\
\hline Mobile & MnerAla010 & UF438829 & Alabama & 10 & MF960131 & MF960172 \\
& MnerAla011 & UF438829 & Alabama & 10 & MF960132 & MF960173 \\
& MnerAla013 & UF438234 & Alabama & 11 & MF960133 & MF960174 \\
& MnerAla027 & UF441128 & Alabama & 12 & MF960134 & MF960175 \\
& MnerAla028 & UF441128 & Alabama & 12 & MF960135 & MF960176 \\
& MnerMob014 & UF438239 & Alabama & 13 & MF960158 & MF960199 \\
\hline
\end{tabular}

